\title{
Proposal of building a standard geodatabase for urban land use
}

\author{
Haifaa Husein ${ }^{1, *}$, Oday Jasim ${ }^{1}$, and Saja Mahmood ${ }^{2}$ \\ ${ }^{1}$ Building and Construction Engineering Department, University of Technology, Baghdad, Iraq \\ ${ }^{2}$ Ministry of Planning, Baghdad, Iraq
}

\begin{abstract}
The digital technologies represented by digital processing programs, local data bases and satellite receivers system is a set of technologies made to organize the process of building descriptive field database, and conveying them to computers, in order to store, analyze and manifest data as well as upgrade and extract it in the form of digital maps, which represent an asset in any engineering and planning study. For a variety of types of mixed land uses and others land uses in the urban city, which cause great difficulty in how to build spatial Geodatabase in terms of frequency of the land use and overlap between land uses, the paper will find the proposed standard Geomatics techniques to get rid of these difficulties. The paper will tackle the engineering and survey methods which could reinforce manifestation of uses of logical database in urban areas. Lastly, the research concludes that relying on important field survey and digital references in preparing suggested criteria for field uses, in addition to the recommendations provided in this field for the post graduate and undergraduate students as well governmental specialized departments.
\end{abstract}

\section{Introduction}

The importance of digital technologies has emerged as an advanced means of handling spatial and the descriptive data in terms of input to the computers, method of storage, processing and analysis of these data, updating and archival on paper and screen in a digital format for the study of various topics, including the preparation of rules standard spatial data for urban land uses. One of the most important of these technologies is GIS technology, Which showed a clear development in the 1980s. One of the most important results is the creation of geographic information systems that can be used through personal computers. The decade of the 1990s has been characterized by the widespread use of geographic information systems (GIS) technologies around the world and the emergence of many manufacturers of cartridges, and a number of complementary technologies for information systems such as global signature system and remote sensing. Using remote sensing techniques, geographical information system algorithms and the global signature system, Geomatics involves a variety of digital techniques that are dedicated to the surface of the earth and the surrounding environment using computers that play an important role in linking digital technology, space and aerial images in such a way as to facilitate access to information for taking decisions. This science deals with many techniques, including the techniques that specialize in the preparation and construction of databases, like spatial sensing, photogrammetry, remote sensing, field survey, geographic information system (GIS) and global positioning system (GPS). This project includes two main aspects - first involves the preparation of a standard spatial database using GIS, while the second includes urban land use. The importance of geographic information systems has emerged as an advanced means of dealing with data in various fields of scientific information, and geographic information systems have helped solve many of the problems of information regulation using the computer and linking it to a geographic perspective, as geography is the link between spatial data, attribute data and statistics. The main objective of the research is to demonstrate the importance of showing the overall structure and important steps to build standards rules spatial data for urban land uses using digital techniques in geomatics to be supplied to Architectural Planning libraries specialized in such courses.

\section{Description of study area}

The project provides a high-resolution aerial location for an urban residential complex (mahala 614) in Baghdad for the year 2009 within the district of Karkh in the direction of Mansour and bounded between latitudes $33^{\circ} 17^{\prime} 24^{\prime \prime}$ and $33^{\circ} 17^{\prime} 21^{\prime \prime}$ north and longitudes $44^{\circ} 19^{\prime} 28^{\prime \prime}$ and $44^{\circ} 20^{\prime} 53^{\prime \prime}$ east. The temporal boundary was limited to the current state of land use in the study area during the year 2016 based on the digital

\footnotetext{
Corresponding author: author@e-mail.org
} 
maps of the image and the preparation of the field survey for the study area is shown in figure (1) through access to below the area of the district in Baghdad city.

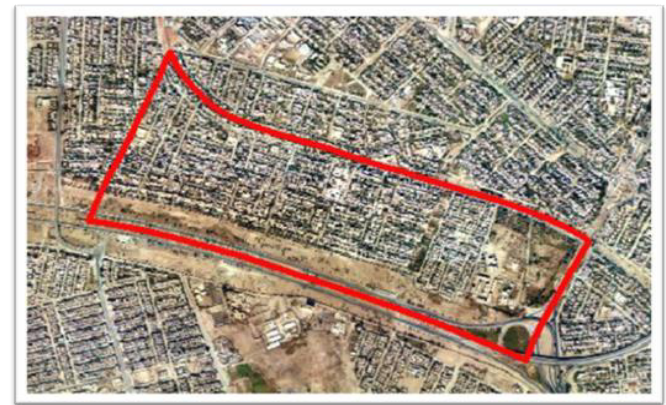

Fig.1. Study area in Baghdad

\section{Land cover land use classification}

A land use and land cover classification system which can effectively employ orbital and high-altitude remote sensor data should meet the following criteria, The minimum level of interpretation accuracy in the identification of land use and land cover categories from remote sensor data. The accuracy of interpretation for the several categories should be about equal, Multiple or mixed uses of land should be recognized when possible. Aggregation of categories must be possible and finally The classification system should be suitable for use with remote sensor data obtained at different times of the year. [1]

The term land use refers to the activities that man performs in a specific spatial and at a specific time. It is known as activities carried out by humans on the ground to which a direct link is related to Classification of land uses. Classification is defined as combining similar observations of individual characteristics into categories and thus, isolating them from other categories. Since, the study of land use and its representation in detail is not an easy process, the classification of these uses is required because it is a way to arrange the uses of the land in certain categories by a specific property for the purpose of achieving the desired goal of the school after obtaining information and data from the field registration of land use survey and updating information for events and services, and placing them locally, these events and information are organized into files within the calculator that are in light of cartographic representation, taking into account the overlap between the uses such as housing, commercial, industry and others services. There are several methods and systems for the classification of land uses such as, Coding System, which is a regulatory tool for recording land uses and is a fast way to access the land uses data and this system will organize these data into spatial groups [2] , the coding system have a great the importance during Field inventory or field survey as converting data from field records to spatial file records as well as its importance in helping facilitate the task of determining the subtypes of the uses for example, a housing code of 10 is used for residential use of one floor, 11 and 12 for two floors and so on. Colouring System is also one of the most important and most widely used systems in the study of land use patterns, but with particular difficulty in terms of the cost of producing the map of land use and introduces with this system the development of certain symbols of coordination with each colour intended for specific use [3]. .Graphic Symbol System is also help to understand the pattern of land use according to the symbols of knowledge, After the system is selected to classify land uses, the information can be simplified and shown on three main groups:

1. Area represent of the land use, housing, industry, commerical ,adminstrative, education etc..

2. Lines represent road networks and lines of all infrastructures.

3. Symbols represent the actual services like the fire station, the water towers, etc.

The methods and systems used in the classification of land uses in some countries are as follows [2]:

- In USA, they used in the past a colour scheme in coding of the land uses .

- At present, the municipalities of Dubai , Egypt and Saudi Arabia have used the symbols and code system to mark land uses in order to standardize the planning indicators, to facilitate their classification, storage, , retrieval and utilization in a unified scientific method that avoids criticism, supports integration, saves time and effort. It establishes an integrated database that supports various development decisions and helps to spread knowledge awareness.

- Based on the Colour System in America and the system of code and symbols tracked in the countries mentioned above, and with the use of Anderson classification of land cover and land use, the researcher will prepare a proposal for the construction of land use databases in the urban city of Iraq using the main Geomatic techniques.

\subsection{Data collection}

The data collection process includes both spatial and attributes types and can be summarized as follows: Spatial Data: Spatial data include high-resolution satellite image of the Area of intreset. This is where the coordinates of the image are corrected as making each point on the map similar to the one on the earth through the process of georeferencing of the aerial image Georeference, which is the first major process to deal with GIS and in this process the metadata will be converted to digital formats that the computer can handle. Attribute Data Collection.This stage was divided into the following two sub stages.

- Stage one: Conducting a ground survey of the area of study in order to determine the land uses for which information must be collected and found such as 
Residential use, commercial use, health use, educational use, Religious use, Recreational use, mixed use, roads, light industries

- Stage two: Designing a questionnaire for the land use survey.

\subsection{Design and construction of GDB}

The Building of Geodatabase of land cover was completed by using the coding of Enderson classification from the interpretation of the image, as well as the Building of Geodatabase for land use by Arc GIS 9.3 and using the Arc catalog where a folder containing two databases of Personal Geodatabase One was called Land use and the other Land cover as shown in figure (2).

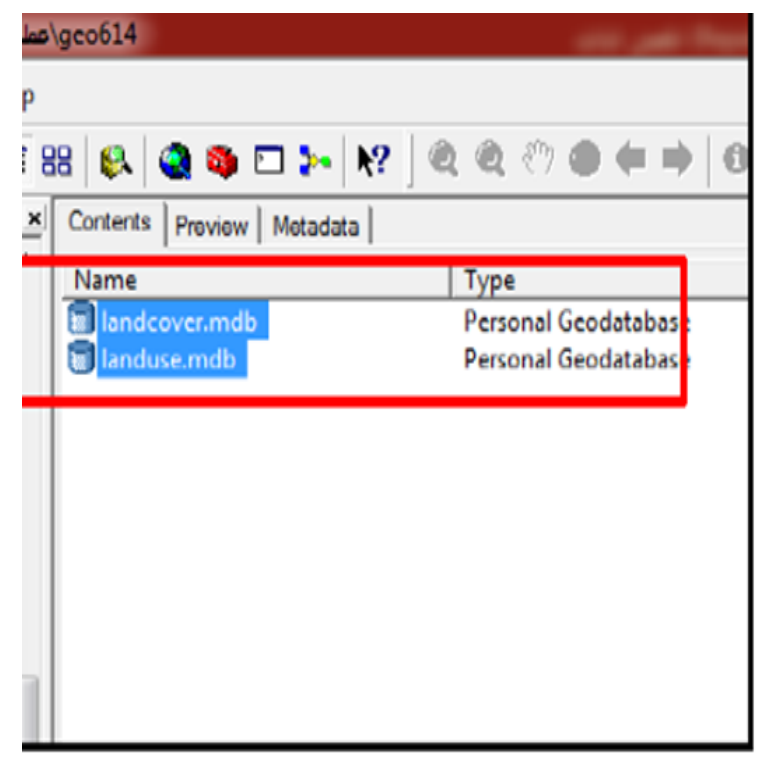

Fig. 2. The two databases land cover, land use

\subsection{Preparing the Spatial Database}

At this stage, the researcher start to draw all features in the land cover and land uses using Arc GIS9.3 program and based on the high resolution image. This geodatabase include a store of geographic data as in feature data set with the set of intgrity of rules (topology) and with a tables represent nongeographic objects.and also these features and data represent as in a domain and subtype stages which is very important in the classifications of the land cover and land use . Figure (3) show the layers of geodatabase of the study area. After collecting the attribute data through the survey of land uses, the data will be entered into the land use database. The sub-type and domain, which is one of the most important features of the personal database, will be used. It facilitates the classification of data and save time and effort of re-writing it, as well as preventing errors while entering the data. Figure $(4,5)$ shows the land cover,land use (LCLI) of the study area.

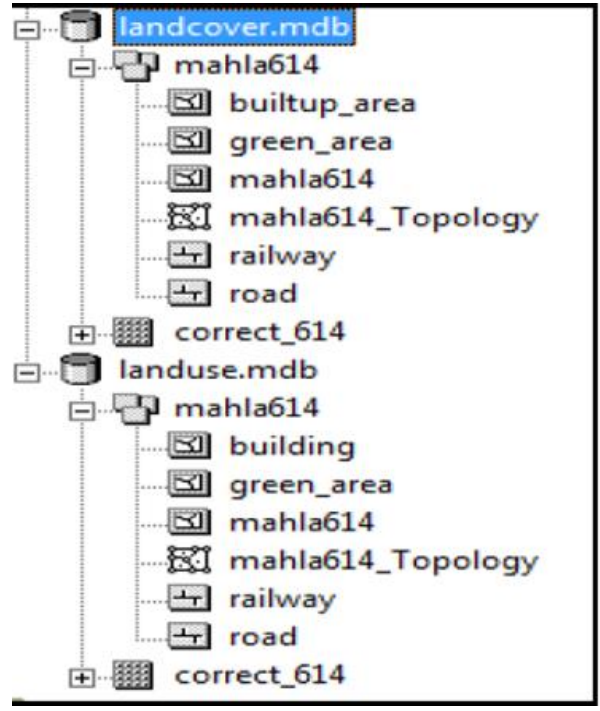

Fig.3. Show the layers of the geodatabase.

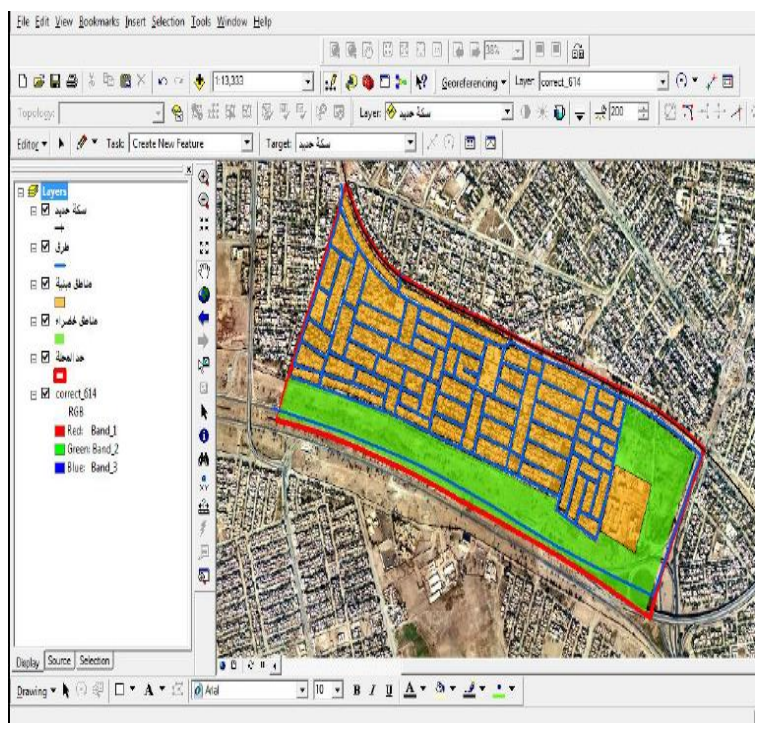

Fig.4. Show the Land cover of the study area.

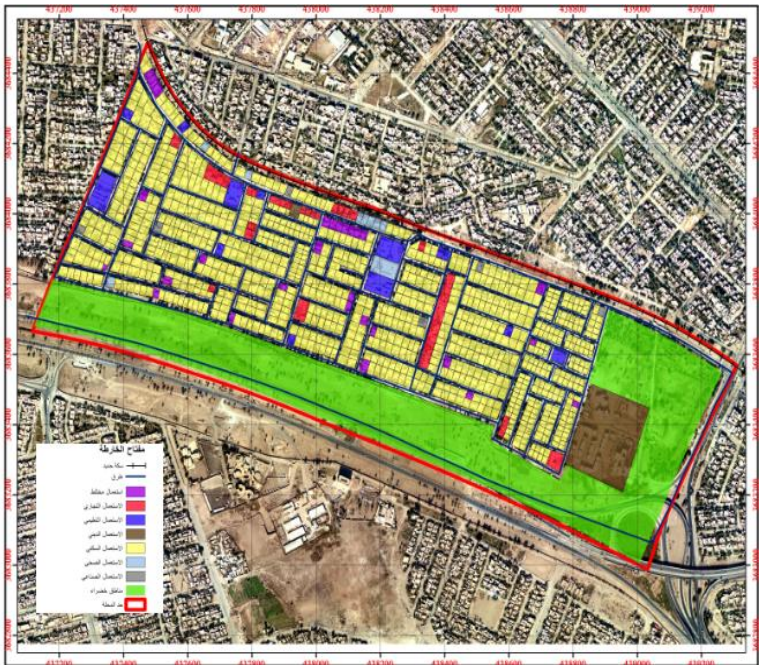

Fig.5. Land use of the study area. 
The subtype is used by the researcher to choose from, and each subtype will have a domain of selections, and this is done in the following steps:

1. The second level table data will be the field to be served with its subtype while the other fields will be domain of this subtype.

2. Chose the layer of buildings in the land use database and select all of the Selected Properties and then select Field and add the fields where data will be entered with Consider field type.

3. Repeat the previous step but choose Subtype and then from the field Subtype choose Landuse-level two 4. Enter the data in the Subtype fields

5. When open a layer that has its Subtype function using the Arc map9.3 note that Choose any type of work to have Subtype and thus save the time and effort of rewriting again.

6. Using the Arc catalog, add the Domain fields by pressing $(\mathrm{RC})$ on the Land use Geodatabase and select Domain and begin adding the third level data with consideration Select the type of short integer field and the code is coded values.

7. Repeat the previous step to create the Domain for the field use-level four.

8. Link the Subtype field to the Domain fields, by selecting the layer of buildings in the land use data and press RC on the properties and then select Properties then choose Subtype after linking the fields.

9. After completing the linking process open the layer using the program Arcmap9.3 note that the existing properties of the Domain that is associated appears with the same field as the Subtype and when the type of the Subtype is changed The Domain field also changes. This is the idea of the Domain \& Subtype for the proposed geodatabase of the Urban land use

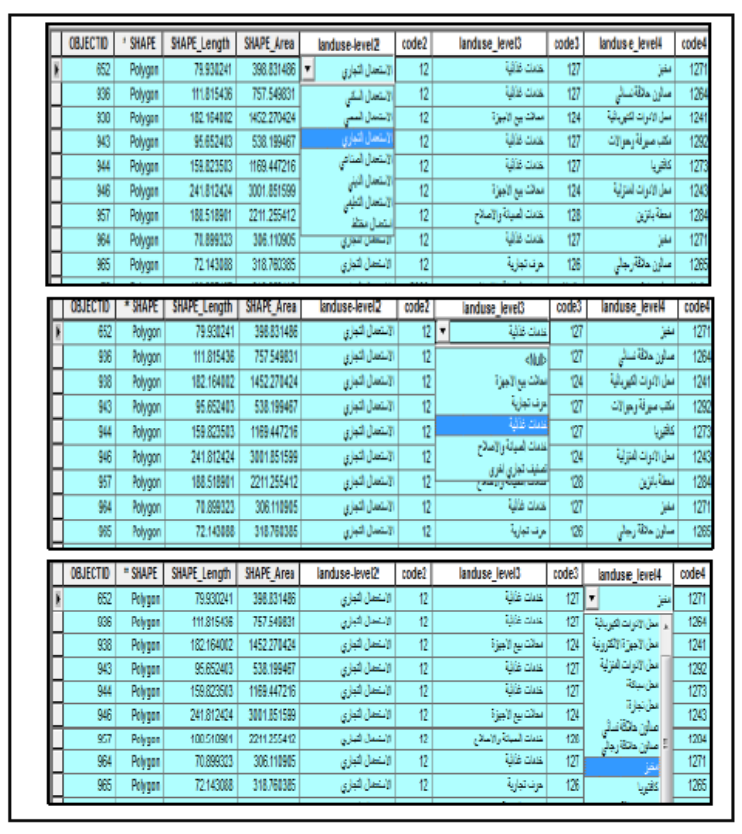

as shown in figure (6).

Fig.6. Proposal geodatabase of urban land use

\subsection{Production of a digital map and thematic maps}

The final outputs are accompanied by digital maps to produce a thematic map of classification Land Cover and Land Use by designing the map according to the standard map production standards using Arc map 9.3 and going to the Layout view With the Insert tool,

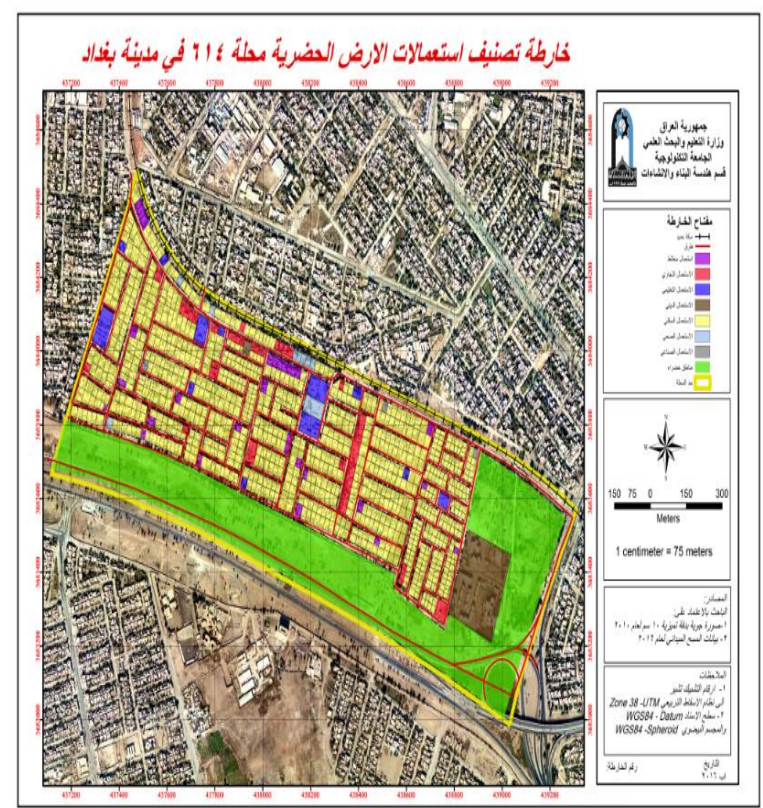

then add the map title, chart, and map information as shown in figure (7)

Fig.7. Final layout of the urban land use map

\section{Summary and Conclusions}

Despite the importance of field survey in the accuracy of access to data, the delay in completing Land surveys and the associated high cost of access to one building in detail, prevent its application in a manner which leaves learners and planners with important data on the reality on the ground and this may lead to the wrong conclusions in these courses and plans. So it is important to introduce digital techniques into Geomatics in the preparation of spatial databases for urban land use. The difficulty of identifying the details of the urban land use has brought this research to necessity to adopt planning criteria to ensure easy access or recognition of the quality of urban land use. The project has reached an understanding of all the standard mechanisms used recently in developed countries and has drawn from them what can be 
incorporated into digital techniques in Geomatics and digital forms. High-resolution data is one of the best ways to get data and information for any area where colourful aerial images give a discriminating ability to locations and spatial phenomena. The ability of digital techniques in Geomatics to provide the possibility of handling and processing a large volume of data, will help to increase the efficiency of urban land use.

\section{References}

1. Anderson, J., Hardy, E., Roach, R. Witmer, USGS, Prof. Pap 964, 5(1983)

2. Stuart F. Chapin, Edward J. Kaiser, Urban Land use planning (university of Illinois, 1972)

3. De C. Joseph, Koppelman L, Planning Design Criteria, (Published by Van Nostrand Reinhold 1969) 